\title{
Pharmacokinetics and Bioequivalence of Sitagliptin Phosphate/ Metformin Hydrochloride Tablets in Healthy Chinese Subjects: A Randomized, Open-Label, Crossover Study
}

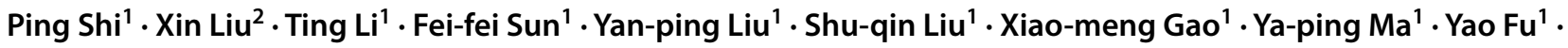 \\ Yu Cao ${ }^{1}$ (D)
}

Accepted: 28 October 2021 / Published online: 30 November 2021

(c) The Author(s) 2021

\begin{abstract}
Objective Our objective was to evaluate the pharmacokinetics and bioequivalence of test and reference (JANUMET ${ }^{\circledR}$ ) formulations of sitagliptin phosphate/metformin hydrochloride tablets at a single dose of $50 \mathrm{mg} / 850 \mathrm{mg}$.

Methods The study was a randomized, open-label, two-period, double-crossover trial. Volunteers under fasting $(n=24)$ and fed $(n=24)$ conditions were given a single oral dose of test or reference formulations of sitagliptin phosphate/metformin hydrochloride tablets $50 \mathrm{mg} / 850 \mathrm{mg}$. We used the liquid chromatography tandem mass spectrometry method to determine the concentrations of sitagliptin and metformin in the plasma of subjects. Pharmacokinetic metrics were calculated using the WinNonlin 7.0 program, and bioequivalence was evaluated using SAS 9.4.

Results Under the fasting condition, the $90 \%$ confidence intervals (CIs) of geometric mean ratio for maximum plasma drug concentration $\left(C_{\mathrm{max}}\right)$, area under the plasma concentration-time curve from time zero to time $t\left(\mathrm{AUC}_{0-t}\right)$, and AUC from time zero to infinity $\left(\mathrm{AUC}_{0-\infty}\right)$ of sitagliptin between the test and reference groups were $101.70-120.62 \%, 99.81-105.61 \%$, and 100.27-106.12\%, respectively; for metformin, they were $90.39-111.48 \%, 94.76-109.12 \%$, and $95.76-110.38 \%$, respectively. Under the fed condition, they were $102.12-117.31 \%, 100.80-107.81 \%$, and 100.82-107.78\%, respectively, for sitagliptin and $95.53-105.22 \%, 92.76-103.07 \%$, and $93.40-104.14 \%$, respectively, for metformin. Both were generally well-tolerated. Conclusion The two formulations of sitagliptin phosphate/metformin hydrochloride tablets were bioequivalent under fasting and fed conditions in healthy Chinese subjects.
\end{abstract}

\section{Introduction}

The number of patients with diabetes worldwide reached 366 million in 2011 and is expected to reach 552 million by 2030 according to the International Diabetes Federation [1]. Type 2 diabetes mellitus (T2DM) accounts for $93.7 \%$ of the total and is currently the fastest-growing and the most studied type of diabetes [2]. Most of the serious complications of diabetes are macrovascular and microvascular diseases caused by accelerated atherosclerosis.

Xin Liu and Ping Shi contributed equally to this work.

Yu Cao

caoyu1767@163.com

1 Clinical Trials Center, The Affiliated Hospital of Qingdao University, Qingdao, Shandong, China

2 School of Pharmacy, Qingdao University, Qingdao, Shandong, China

\section{Key Points}

The test and reference formulations of sitagliptin phosphate/metformin hydrochloride tablets were bioequivalent in healthy Chinese subjects. The $90 \%$ confidence intervals for geometric mean ratios of sitagliptin and metformin maximum plasma drug concentration, area under the plasma concentration-time curve (AUC) from time zero to time $t$, and AUC from time zero to infinity were within the bioequivalence range $(0.80-1.25)$.

Metabolism of both the test and the reference formulation was affected by food. 


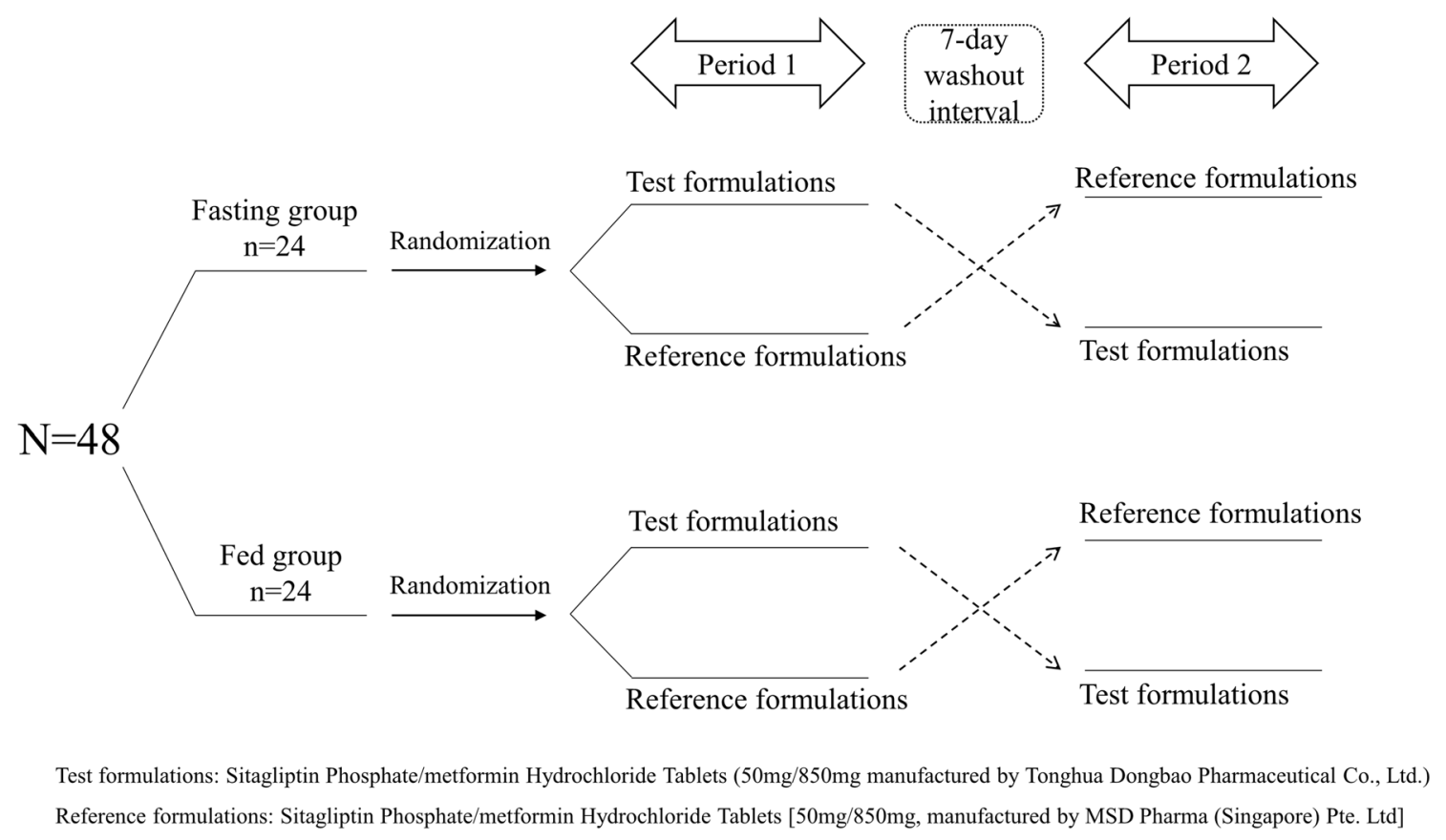

Fig. 1 Schematic representation of the study design

Cardiovascular morbidity is two to four times higher in people with T2DM than in people without diabetes [3].

Almost all guidelines for the initial treatment of T2DM recommend metformin, which is widely used in clinic [4]. However, metformin alone often fails to meet the basic requirements for glycemic control [5]. Therefore, oral hypoglycemic drugs are used in combination to effectively manage the blood glucose of patients with diabetes. Hypoglycemic drugs commonly used in combination include sulfonylureas, acarbose, dipeptidyl peptidase-4 inhibitors (DPP-4i), glucagon-like peptide-1 receptor agonists (GLP-1 RAs), and sodium-glucose co-transporter-2 inhibitors (SGLT-2).

Sitagliptin has shown strong and highly selective inhibition of DPP-4 [6]. DPP-4i have a wide range of therapeutic applications. The risk of hypoglycemia is low when used alone or in combination with other drugs that do not cause hypoglycemia. DPP-4 did not cause weight gain [4]. Sitagliptin improves glycemic control by inhibiting DPP-4 inactivation of GLP-1 and glucose-dependent insulinotropic ploypeptide. Inhibition of DPP-4 increases and prolongs the activity level of incretin, leading to a glucosedependent increase in insulin release and a decrease in glucagon [7].

The combination of sitagliptin and metformin has been shown to have a significant effect on blood glucose control in patients with T2DM and is well-tolerated with a low risk of hypoglycemia [8]. Sitagliptin phosphate/metformin hydrochloride tablets are more effective than any single ingredient for the control of blood glucose in patients with T2DM [9]. Sitagliptin phosphate/metformin hydrochloride tablets (JANUMET ${ }^{\circledR}$ ) have been approved for the treatment of T2DM. The purpose of this study was to study the pharmacokinetics and bioequivalence of the test and reference formulations of sitagliptin and metformin 50 $\mathrm{mg} / 850 \mathrm{mg}$ tablets.

\section{Methods}

\subsection{Compliance with Ethics Guidelines}

This clinical study protocol was approved by the Medical Ethics Committee at the Affiliated Hospital of Qingdao University, Shandong, China, and the trial was registered with the Clinical Trial Registry (ID: NCT04877106). All procedures were performed in compliance with the Declaration of Helsinki [10] and the International Conference on Harmonization Guidelines for Good Clinical Practice [11]. All subjects provided written informed consent before being screened for eligibility.

\subsection{Study Population}

Eligible study participants included healthy male and female subjects aged $18-45$ years with a body mass index (BMI) of 

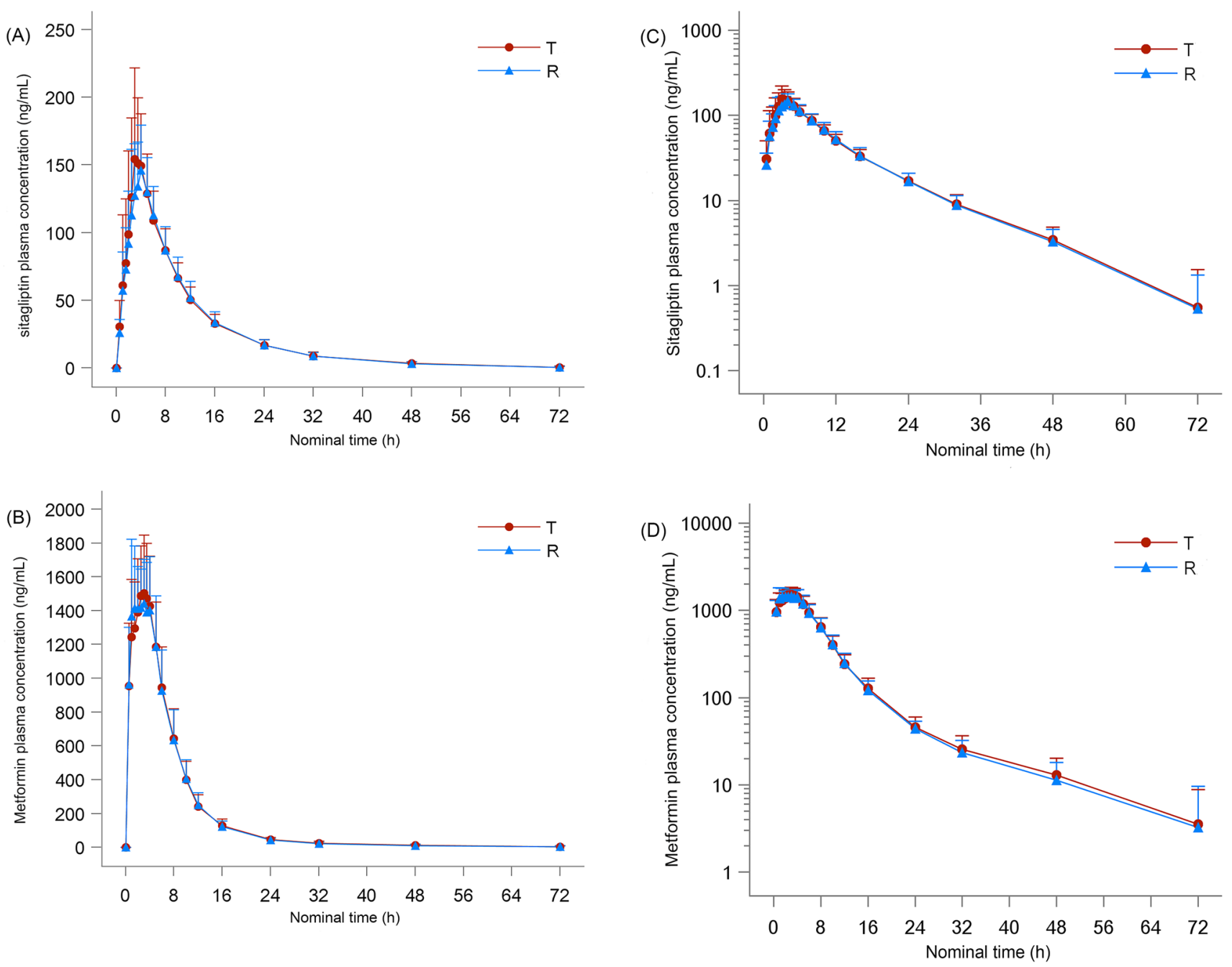

Fig. 2 Plasma concentration-time curve of sitagliptin and metformin following a single dose of test or reference formulations in the fasting group

$18-28 \mathrm{~kg} / \mathrm{m}^{2}$. Both male and female subjects were willing to have no family planning and to voluntarily use effective contraceptive measures for the next 6 months. Subjects signed the informed consent before the trial and were provided with full information about the content, process, and possible adverse reactions. The exclusion criteria included allergy to study medications, smoking, alcohol abuse, participation in another clinical trial within 3 months, pregnant or nursing females, and use of prescription or nonprescription drugs (including herbal remedies).

\subsection{Study Design}

This was an open-label, randomized, single-dose, twoperiod, crossover study conducted at the Phase I Clinical Research Center of the Affiliated Hospital of Qingdao University. Randomization was conducted by the investigators

Fig. 3 Semi-logarithmic curve of sitagliptin and metformin following a single dose of test or reference formulations in the fasting group

in accordance with a randomization schedule created using SAS 9.4 Proc Plan by the statistical analysis unit for fasting and fed conditions, respectively.

In this study, we used sitagliptin phosphate/metformin hydrochloride tablets $50 \mathrm{mg} / 850 \mathrm{mg}$ (batch no. M047893; MSD Pharma (Singapore) Pte. Ltd) as reference formulations and sitagliptin phosphate/metformin hydrochloride tablets $50 \mathrm{mg} / 850 \mathrm{mg}$ (batch no. 161006; Tonghua Dongbao Pharmaceutical Co., Ltd.) as test formulations. All study drugs were provided by the sponsor (Tonghua Dongbao Pharmaceutical Co., Ltd.) at no cost. All subjects were hospitalized in the phase I clinical research center on the day before dosing and placed on a uniform diet during hospitalization. Subjects in the fasting group (24 subjects) were asked to fast overnight $(10 \mathrm{~h}$ ) before administration, and subjects in the fed group (24 subjects) consumed an additional high-fat, high-calorie standard meal $30 \mathrm{~min}$ before drug administration. Test and reference formulations of sitagliptin 
Table 1 Pharmacokinetic metrics of test and reference formulations of sitagliptin and metformin in the fasting and fed groups

\begin{tabular}{|c|c|c|c|c|}
\hline \multirow[t]{2}{*}{ Metrics } & \multicolumn{2}{|l|}{ Fasting group $(n=23)$} & \multicolumn{2}{|l|}{ Fed group $(n=23)$} \\
\hline & Test & Reference & Test & Reference \\
\hline \multicolumn{5}{|l|}{ Sitagliptin } \\
\hline$C_{\max }(\mathrm{ng} / \mathrm{mL})$ & $182.37 \pm 63.53(34.8)$ & $162.93 \pm 37.16(22.8)$ & $201.379 \pm 39.667(19.7)$ & $181.746 \pm 33.439(18.4)$ \\
\hline $\mathrm{AUC}_{0-t}(\mathrm{~h} \times \mathrm{ng} / \mathrm{mL})$ & $1704.19 \pm 32.54(19.5)$ & $1676.46 \pm 269.80(16.1)$ & $1727.80 \pm 258.28(14.9)$ & $1665.89 \pm 256.74(15.4)$ \\
\hline $\mathrm{AUC}_{0-\infty}(\mathrm{h} \times \mathrm{ng} / \mathrm{mL})$ & $1744.90 \pm 35.79(19.2)$ & $1710.12 \pm 273.94(16.0)$ & $1762.92 \pm 257.47(14.6)$ & $1699.38 \pm 254.27(15.0)$ \\
\hline$t_{1 / 2}(\mathrm{~h})$ & $11.04 \pm 2.98(27.0)$ & $10.61 \pm 2.80(26.4)$ & $11.98 \pm 2.59(21.6)$ & $11.96 \pm 3.93(32.8)$ \\
\hline \multicolumn{5}{|l|}{ Metformin } \\
\hline$C_{\max }(\mathrm{ng} / \mathrm{mL})$ & $1658.71 \pm 314.76(19.0)$ & $1666.23 \pm 330.44(19.8)$ & $1270.960 \pm 205.903(16.2)$ & $1261.443 \pm 184.167(14.6)$ \\
\hline $\mathrm{AUC}_{0-t}\left(\times 10^{4} \mathrm{~h} \times \mathrm{ng} / \mathrm{mL}\right)$ & $1.29 \pm 0.24(18.5)$ & $1.27 \pm 0.24(19.0)$ & $1.14 \pm 0.20(17.7)$ & $1.16 \pm 0.19(16.3)$ \\
\hline $\mathrm{AUC}_{0-\infty}\left(\times 10^{4} \mathrm{~h} \times \mathrm{ng} / \mathrm{mL}\right)$ & $1.32 \pm 0.25(18.9)$ & $1.29 \pm 0.25(19.1)$ & $1.17 \pm 0.22(18.5)$ & $1.19 \pm 0.19(16.1)$ \\
\hline$t_{1 / 2}(\mathrm{~h})$ & $16.77 \pm 15.73(93.8)$ & $10.69 \pm 5.12(47.8)$ & $18.42 \pm 18.81(102.1)$ & $14.97 \pm 11.30(75.5)$ \\
\hline
\end{tabular}

Data are presented as arithmetic mean \pm standard deviation (\% coefficient of variation)

$A U C$ area under the plasma concentration-time curve, $A U C_{0-t} \mathrm{AUC}$ from time zero to time t, $A U C_{0-\infty} \mathrm{AUC}$ from time zero to infinity, $C_{m a x}$ maximum plasma drug concentration, $t_{1 / 2}$ elimination half-life

Table 2 Geometric mean, ratio, and $90 \%$ confidence intervals of $\mathrm{C}_{\max }, \mathrm{AUC}_{0-t}$, and $\mathrm{AUC}_{0-\infty}$ in the fasting group $(n=23)$

\begin{tabular}{|c|c|c|c|c|c|}
\hline \multirow[t]{2}{*}{ Metrics } & \multicolumn{3}{|c|}{ Geometric mean and ratio } & \multirow{2}{*}{$\begin{array}{l}\text { Intrasubject } \\
\mathrm{CV}(\%)\end{array}$} & \multirow[t]{2}{*}{ GMR $(90 \% \mathrm{CI})$} \\
\hline & Test & Reference & $\mathrm{T} / \mathrm{R} \%$ & & \\
\hline \multicolumn{6}{|l|}{ Sitagliptin } \\
\hline$C_{\max }(\mathrm{ng} / \mathrm{mL})$ & 175.62 & 158.56 & 110.76 & 16.91 & $101.70-120.62$ \\
\hline $\mathrm{AUC}_{0-t}(\mathrm{~h} \times \mathrm{ng} / \mathrm{mL})$ & 1701.90 & 1657.68 & 102.67 & 5.57 & $99.81-105.61$ \\
\hline $\mathrm{AUC}_{0-\infty}(\mathrm{h} \times \mathrm{ng} / \mathrm{mL})$ & 1744.48 & 1691.14 & 103.15 & 5.59 & $100.27-106.12$ \\
\hline \multicolumn{6}{|l|}{ Metformin } \\
\hline$C_{\max }(\mathrm{ng} / \mathrm{mL})$ & 1642.07 & 1635.80 & 100.38 & 20.36 & $90.39-111.48$ \\
\hline $\mathrm{AUC}_{0-t}\left(\times 10^{4} \mathrm{~h} \times \mathrm{ng} / \mathrm{mL}\right)$ & $12,804.86$ & $12,591.94$ & 101.69 & 13.63 & $94.76-109.12$ \\
\hline $\mathrm{AUC}_{0-\infty}\left(\times 10^{4} \mathrm{~h} \times \mathrm{ng} / \mathrm{mL}\right)$ & $13,072.84$ & $12,715.42$ & 102.81 & 13.72 & $95.76-110.38$ \\
\hline
\end{tabular}

$A U C$ area under the plasma concentration-time curve, $A U C_{0-t}$ AUC from time zero to time t, $A U C_{0-\infty}$ AUC from time zero to infinity, $C I$ confidence interval, $C_{\max }$ maximum plasma drug concentration, $C V$ coefficient of variation, GMR geometric mean ratio, $R$ reference, $T$ test, $t_{1 / 2}$ elimination half-life phosphate/metformin hydrochloride tablets were swallowed with $240 \mathrm{~mL}$ water at room temperature. Subjects were allocated to one of two groups randomly and equally with a 7-day washout interval between the two periods (Fig. 1).

Subjects were prohibited from consuming caffeinecontaining beverages, food rich in methylxanthine, fruits that affect drug metabolism (e.g., grapefruit, dragon fruit, mango), and alcohol from $48 \mathrm{~h}$ prior to dosing to completion of blood sampling.

\subsection{Blood Sampling}

Blood samples $(4 \mathrm{~mL})$ were collected in vacuum tubes containing EDTA- $\mathrm{K}_{2}$ at predosing $(0 \mathrm{~h})$ and $0.5,1,1.5,2,2.5$, $3,3.5,4,5,6,8,10,12,16,24,32,38$, and $72 \mathrm{~h}$ after dosing in each study period. The samples were centrifuged at 1710 $g$ for $10 \mathrm{~min}$ at $2-8{ }^{\circ} \mathrm{C}$ to separate the plasma. Samples were divided into two aliquots and stored at $-80^{\circ} \mathrm{C}$ until analysis.

\subsection{Pharmacokinetic Methods}

Plasma samples were determined at Junke Zhengyuan (Beijing) Pharmaceutical Research Co., Ltd. and analyzed using liquid chromatography tandem mass spectrometry (LC-MS/MS) methods, which were validated in terms of selectivity, accuracy, precision, recovery, and stability. The LC-MS/MS system consisted of a Shimadzu UFLC 20-AD ultrafast liquid phase system (Shimadzu Corp., Kyoto, Japan) and API 4000 mass spectrometer (Applied Biosystems, MDS Sciex). For metformin, mobile phase A consisted of $0.1 \%$ formic acid (by volume) containing $5 \mathrm{mM}$ ammonium acetate; mobile phase B consisted of $0.1 \%$ formic acid (by volume) in acetonitrile. For sitagliptin, mobile phase A consisted of $0.1 \%$ formic acid (by volume) in water; mobile phase B consisted of $0.1 \%$ formic acid (by volume) in acetonitrile. API 4000 was operated in the positive ion multiple reaction monitoring mode using 

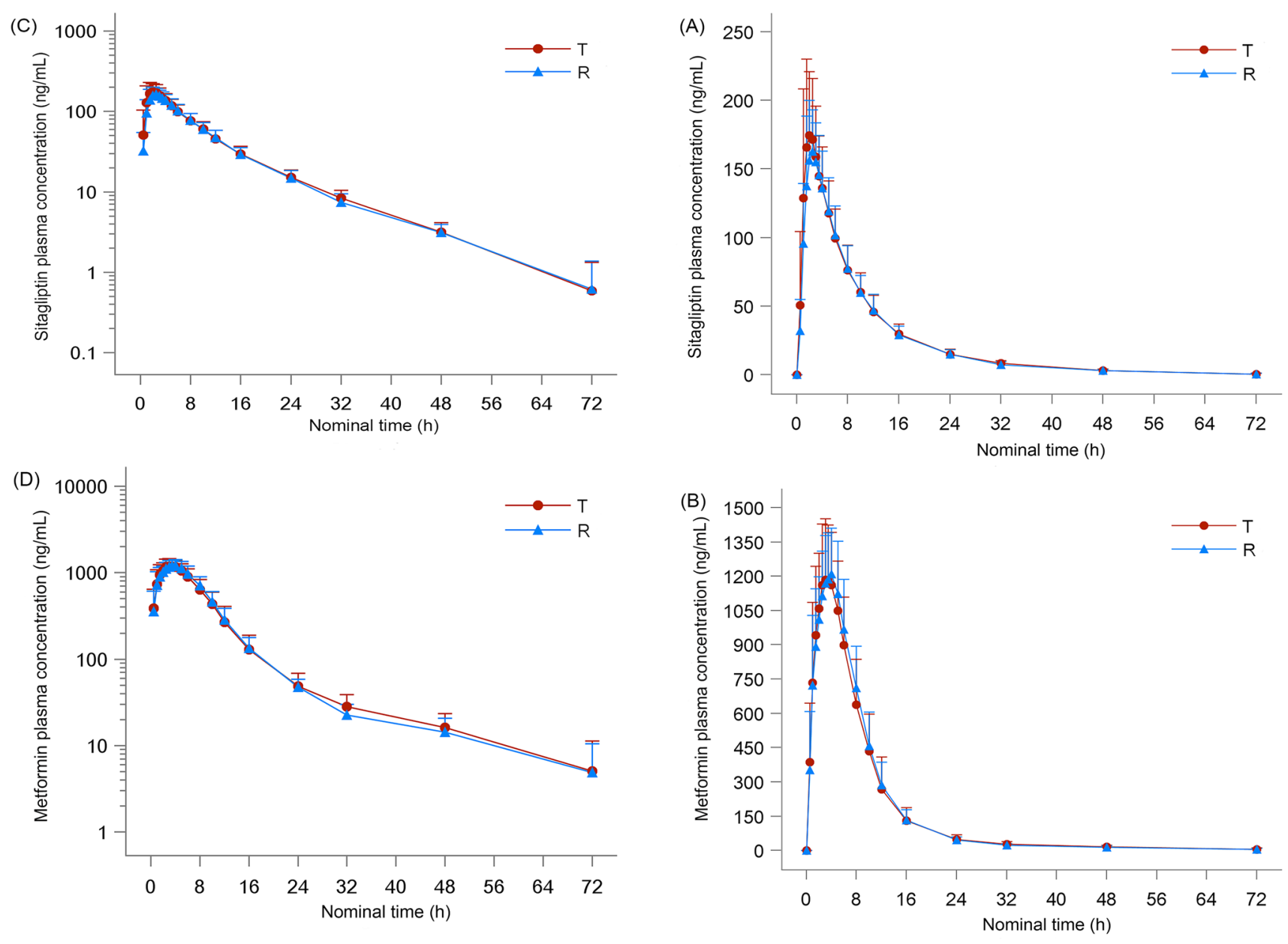

Fig. 5 Semi-logarithmic curve of sitagliptin and metformin following a single dose of test or reference formulations in the fed group

Fig. 4 Plasma concentration-time curve of sitagliptin and metformin following a single dose of test or reference formulations in the fed group

Turbo Spray. The lower limit of quantification (LLQ) for metformin in the plasma assay was $3 \mathrm{ng} / \mathrm{mL}$, and the linear calibration range was $3-1500 \mathrm{ng} / \mathrm{mL}$. The overall precision of the metformin assay was $8.9 \%$ coefficient of variation (CV). The LLQ for sitagliptin in the plasma assay was 1 $\mathrm{ng} / \mathrm{mL}$, and the linear calibration range was $1-500 \mathrm{ng} / \mathrm{mL}$. The overall precision of the sitagliptin assay was $5.8 \% \mathrm{CV}$.

\subsection{Safety and Tolerability Assessments}

Data from all study participants were included in safety and tolerability assessments. Safety was evaluated through subject-reported adverse events (AEs), investigator observations and assessments, and prespecified study evaluations (laboratory safety tests, electrocardiograms, and vital sign measurements). Safety and tolerability were evaluated through clinical review of all safety metrics.

\subsection{Statistical Analysis}

Analysis of variance (ANOVA) was performed on the logarithmically transformed values of the primary pharmacokinetic metrics (maximum plasma drug concentration $\left[C_{\max }\right]$, area under the plasma concentration-time curve from time zero to $\mathrm{t}\left[\mathrm{AUC}_{0-t}\right]$, and $\mathrm{AUC}$ from time zero to infinity $\left.\left[\mathrm{AUC}_{0-\infty}\right]\right)$. The ratios of geometric means (GMs) of these primary pharmacokinetic metrics (test/reference) and their $90 \%$ confidence intervals (CIs) were calculated. The two preparations were considered bioequivalent if the $90 \%$ CIs of the ratios of GM of the primary pharmacokinetic metrics were within the predefined acceptance range of $80-125 \%$. All pharmacokinetic parameter analysis was calculated using WinNonlin 7.0, and other data processing and statistical analyses were performed using SAS 9.4. 
Table 3 Geometric mean, ratio, and $90 \%$ confidence intervals of $C_{\text {max }}, \mathrm{AUC}_{0-t}$, and $\mathrm{AUC}_{0-\infty}$ in the fed group $(n=23)$
Table 4 Adverse events in the fasting group

Table 5 Adverse events in the fed group

\begin{tabular}{|c|c|c|c|c|c|}
\hline \multirow[t]{2}{*}{ Metrics } & \multicolumn{3}{|c|}{ Geometric mean and ratio } & \multirow{2}{*}{$\begin{array}{l}\text { Intrasubject } \\
\mathrm{CV}(\%)\end{array}$} & \multirow[t]{2}{*}{ GMR $(90 \%$ CI) } \\
\hline & Test & Reference & $\mathrm{T} / \mathrm{R} \%$ & & \\
\hline \multicolumn{6}{|l|}{ Sitagliptin } \\
\hline$C_{\max }(\mathrm{ng} / \mathrm{mL})$ & 198.05 & 180.95 & 109.45 & 13.34 & $102.12-117.31$ \\
\hline $\mathrm{AUC}_{0-t}(\mathrm{~h} \times \mathrm{ng} / \mathrm{mL})$ & 1725.22 & 1654.92 & 104.25 & 6.44 & $100.80-107.81$ \\
\hline $\mathrm{AUC}_{0-\infty}(\mathrm{h} \times \mathrm{ng} / \mathrm{mL})$ & 1760.75 & 1689.12 & 104.24 & 6.41 & $100.82-107.78$ \\
\hline \multicolumn{6}{|l|}{ Metformin } \\
\hline$C_{\max }(\mathrm{ng} / \mathrm{mL})$ & 1256.10 & 1252.84 & 100.26 & 9.27 & $95.53-105.22$ \\
\hline $\mathrm{AUC}_{0-t}\left(\times 10^{4} \mathrm{~h} \times \mathrm{ng} / \mathrm{mL}\right)$ & $11,231.03$ & $11,485.70$ & 97.78 & 10.11 & $92.76-103.07$ \\
\hline $\mathrm{AUC}_{0-\infty}\left(\times 10^{4} \mathrm{~h} \times \mathrm{ng} / \mathrm{mL}\right)$ & $11,544.32$ & $11,705.72$ & 98.62 & 10.45 & $93.40-104.14$ \\
\hline
\end{tabular}

$A U C$ area under the plasma concentration-time curve, $A U C_{0-t}$ AUC from time zero to time $\mathrm{t}, A U C_{0-\infty} \mathrm{AUC}$ from time zero to infinity, $C I$ confidence interval, $C_{\max }$ maximum plasma drug concentration, $C V$ coefficient of variation, $G M R$ geometric mean ratio, $T / R$ test/reference, $t_{1 / 2}$ elimination half-life

\begin{tabular}{llll}
\hline Random number & AEs & Treatment & Relationship to study drug \\
\hline K009 & Nodal tachycardia & $\mathrm{R}$ & Probably related \\
K016 & Nausea & $\mathrm{T}$ & May be irrelevant \\
& Hyperuricemia & $\mathrm{R}$ & Probably related \\
K017 & Nausea & Before treatment & Definitely not \\
K020 & Dizziness & Before treatment & Definitely not \\
K024 & Hyperuricemia & $\mathrm{T}$ & Probably related \\
\hline
\end{tabular}

$A E$ adverse event, $R$ reference, $T$ test

\begin{tabular}{llll}
\hline Random number & AEs & Treatment & Relationship to study drug \\
\hline $\mathrm{C} 001$ & Hyperpotassemia & $\mathrm{R}$ & Probably related \\
$\mathrm{C} 004$ & Nodal tachycardia & $\mathrm{R}$ & Definitely not \\
$\mathrm{C} 016$ & Urinary leukocytosis & $\mathrm{R}$ & Probably related \\
$\mathrm{C} 023$ & Borderline premature beats & $\mathrm{R}$ & Probably related \\
\hline
\end{tabular}

$A E$ adverse event, $R$ reference

\section{Results}

\subsection{Subject Disposition}

The overall study population included 48 subjects (fasting group $n=24$, fed group $n=24)$. All 24 subjects (14 male, 10 female) in the fasting group completed the study. The mean \pm standard deviation (SD) demographic details were as follows: age $28.9 \pm 8.28$ years, height $166.17 \pm 7.299$ $\mathrm{cm}$, weight $61.54 \pm 7.699 \mathrm{~kg}$, and BMI $22.25 \pm 1.789 \mathrm{~kg} /$ $\mathrm{m}^{2}$. A total of 24 healthy subjects ( 15 male, 9 female) were enrolled in the fed group; 23 subjects completed the two treatment periods, and one subject withdrew during the baseline before the second treatment period. The mean \pm SD demographic details were as follows: age $25.6 \pm 4.69$ years, height $168.27 \pm 10.140 \mathrm{~cm}$, weight $62.56 \pm 8.779$ $\mathrm{kg}$, BMI $22.03 \pm 1.850 \mathrm{~kg} / \mathrm{m}^{2}$.

\subsection{Pharmacokinetics}

\subsubsection{Fasting Group}

Figures 2 and 3 show the plasma concentration-time profiles under fasting conditions for sitagliptin and metformin, respectively.

Table 1 summarizes the pharmacokinetic metrics for sitagliptin and metformin. ANOVA indicated a lack of period and sequence effects for $C_{\text {max }}, \mathrm{AUC}_{0-t}$, and $\mathrm{AUC}$ $0_{0-\infty}$. There was a statistically significant difference between formulations in $C_{\max }, \mathrm{AUC}_{0-t}$, and $\mathrm{AUC}_{0-\infty}(p \leq 0.05)$. Table 2 presents the $90 \%$ CIs for the geometric mean ratios of $C_{\max }, \mathrm{AUC}_{0-t}$, and $\mathrm{AUC}_{0-\infty}$ and the detailed pharmacokinetic metrics of the two drugs; all were within the predefined equivalence limit of 0.80-1.25. 
Table 6 Comparisons of primary pharmacokinetic metrics of the test and reference formulations under fasted and fed conditions

\begin{tabular}{|c|c|c|c|}
\hline Metrics & Fasting & Fed & $P$ value \\
\hline \multicolumn{4}{|l|}{ T sitagliptin } \\
\hline$C_{\max }(\mathrm{ng} / \mathrm{mL})$ & $182.37 \pm 63.53$ & $201.38 \pm 39.667$ & 0.227 \\
\hline $\mathrm{AUC}_{0-t}(\mathrm{ng} \times \mathrm{h} / \mathrm{mL})$ & $1704.19 \pm 332.54$ & $1727.80 \pm 258.28$ & 0.788 \\
\hline $\mathrm{AUC}_{0-\infty}(\mathrm{ng} \times \mathrm{h} / \mathrm{mL})$ & $1744.89 \pm 335.79$ & $1762.92 \pm 257.47$ & 0.838 \\
\hline$t_{\max }(\mathrm{h})$ & $3.25 \pm 0.87$ & $2.11 \pm 1.16$ & 0.001 \\
\hline \multicolumn{4}{|l|}{$\mathrm{T}$ metformin } \\
\hline$C_{\max }(\mathrm{ng} / \mathrm{mL})$ & $1658.71 \pm 314.76$ & $1270.96 \pm 205.90$ & 0.000 \\
\hline $\mathrm{AUC}_{0-t}\left(\times 10^{4} \mathrm{ng} \times \mathrm{h} / \mathrm{mL}\right)$ & $1.29 \pm 0.24$ & $1.14 \pm 0.20$ & 0.021 \\
\hline $\mathrm{AUC}_{0-\infty}\left(\times 10^{4} \mathrm{ng} \times \mathrm{h} / \mathrm{mL}\right)$ & $1.32 \pm 0.25$ & $1.17 \pm 0.22$ & 0.034 \\
\hline$t_{\max }(\mathrm{h})$ & $2.80 \pm 0.95$ & $3.27 \pm 0.96$ & 0.108 \\
\hline \multicolumn{4}{|l|}{$\mathrm{R}$ sitagliptin } \\
\hline$C_{\max }(\mathrm{ng} / \mathrm{mL})$ & $162.93 \pm 37.16$ & $181.75 \pm 33.44$ & 0.078 \\
\hline $\mathrm{AUC}_{0-t}(\mathrm{ng} \times \mathrm{h} / \mathrm{mL})$ & $1676.47 \pm 269.80$ & $1665.89 \pm 256.74$ & 0.892 \\
\hline $\mathrm{AUC}_{0-\infty}(\mathrm{ng} \times \mathrm{h} / \mathrm{mL})$ & $1710.13 \pm 273.94$ & $1699.38 \pm 254.27$ & 0.891 \\
\hline$t_{\max }(\mathrm{h})$ & $3.50 \pm 0.87$ & $2.41 \pm 0.78$ & 0.000 \\
\hline \multicolumn{4}{|l|}{$\mathrm{R}$ metformin } \\
\hline$C_{\max }(\mathrm{ng} / \mathrm{mL})$ & $1666.23 \pm 330.44$ & $1261.44 \pm 184.17$ & 0.000 \\
\hline $\mathrm{AUC}_{0-t}\left(\times 10^{4} \mathrm{ng} \times \mathrm{h} / \mathrm{mL}\right)$ & $1.27 \pm 0.24$ & $1.16 \pm 0.19$ & 0.099 \\
\hline $\mathrm{AUC}_{0-\infty}\left(\times 10^{4} \mathrm{ng} \times \mathrm{h} / \mathrm{mL}\right)$ & $1.29 \pm 0.25$ & $1.19 \pm 0.19$ & 0.132 \\
\hline$t_{\max }(\mathrm{h})$ & $2.52 \pm 1.15$ & $3.54 \pm 1.02$ & 0.003 \\
\hline
\end{tabular}

$A U C$ area under the plasma concentration-time curve, $A U C_{0-t} \mathrm{AUC}$ from time zero to time $\mathrm{t}, A U C_{0-\infty} \mathrm{AUC}$ from time zero to infinity, $C I$ confidence interval, $C_{\max }$ maximum plasma drug concentration, $R$ reference, $T$ test, $t_{\max }$ time to $\mathrm{C}_{\max }$

\subsubsection{Fed Group}

Figures 4 and 5 show the mean plasma concentration-time profiles under fed conditions for sitagliptin and metformin, respectively.

Table 1 summarizes the pharmacokinetic metrics for sitagliptin and metformin. ANOVA indicated a lack of period and sequence effects for $C_{\max }, \mathrm{AUC}_{0-t}$, and $\mathrm{AUC}_{0-\infty}$. There was a statistically significant difference between formulations in $C_{\text {max }}, \mathrm{AUC}_{0-t}$, and $\mathrm{AUC}_{0-\infty}(p \leq 0.05)$. Table 3 presents the $90 \%$ CIs for the geometric mean ratios of $C_{\max }$, $\mathrm{AUC}_{0-t}$, and $\mathrm{AUC}_{0-\infty}$ and the detailed pharmacokinetic metrics of the two drugs; all were within the predefined equivalence limit of $0.80-1.25$.

\subsection{Safety and Tolerability}

Both test and reference formulations were generally well-tolerated during the entire study periods. No protocol violations or serious AEs (SAEs) were observed in the study under either fasting or fed conditions. Four volunteers experienced a total of four AEs in the fasting and fed groups, respectively. Tables 4 and 5 show these AEs.

\subsection{Effect of Food on Pharmacokinetics}

The effect of food on the pharmacokinetics of test and reference formulations was further explored. Table 6 shows the comparisons of primary pharmacokinetic metrics of the test and reference formulations under fasting and fed conditions. The time to $C_{\max }\left(t_{\max }\right)$ of test formulations of sitagliptin reduced in the presence of food, and the differences were statistically significant $(p<0.05) . \mathrm{C}_{\max }, \mathrm{AUC}_{0-t}$, and AUC ${ }_{0-\infty}$ of metformin test formulations were also statistically significant $(p<0.05)$. However, food did not significantly alter the $t_{\max }$ metformin test formulations. The effect of food on the $t_{\max }$ of sitagliptin and metformin reference formulation was statistically significant $(p<0.05)$, which was different from that of the test formulations. 


\section{Discussion}

T2DM is a complex metabolic disease with an increasing number of patients each year [12]. Sitagliptin is a DPP-4, a newer treatment for T2DM [13], and metformin hydrochloride is a biguanide, widely viewed as foundation therapy for T2DM [14]. More and more research suggests that combination tablets will be an increasingly common strategy for the treatment of T2DM [8]. The sitagliptin/metformin combination has become an important treatment for T2DM [15]. In this study, sitagliptin and metformin levels in plasma were quantitatively analyzed, the pharmacokinetic characteristics and safety of domestic and original sitagliptin phosphate/ metformin hydrochloride tablets were investigated, and the bioequivalence of the two preparations was evaluated.

Here, we assessed the bioequivalence of sitagliptin phosphate/metformin hydrochloride tablets under fasting and fed conditions in healthy Chinese subjects following a single oral dose of $50 \mathrm{mg} / 850 \mathrm{mg}$ test (Tonghua Dongbao Pharmaceutical Co., Ltd.) and reference (MSD Pharma (Singapore) Pte. Ltd) formulations. The two medicinal products are bioequivalent when the $90 \% \mathrm{CIs}$ of the $\mathrm{AUC}_{0-t}, \mathrm{AUC}_{0-\infty}$, and $C_{\max }$ of the reference preparation over the test preparation fall between the predetermined limits of $80-125 \%$.

Our results indicate that both formulations were welltolerated, and no SAEs were observed during the study. All reported AEs were of mild intensity, and no subjects withdrew from the study because of any AEs. The main adverse drug reactions were nausea, hyperuricemia, and hyperkalemia. Most of the adverse drug reactions in this trial were similar to those reported in the literature, indicating that the test and reference formulations have good safety and tolerability in healthy Chinese subjects [16]. The reference formulation specifications and previous literature have reported that food can decrease metformin absorption and slightly delay absorption [17]. The main pharmacokinetic metrics of oral reference metformin formulations in the fed group were significantly lower than those in the fasting group; $C_{\max }, \mathrm{AUC}_{0-t}$, and $\mathrm{AUC}_{0-\infty}$ were significantly lower. Metformin is usually recommended to be taken with meals to improve gastrointestinal tolerance. At the same time, food does not affect the pharmacokinetics of sitagliptin. Therefore, sitagliptin phosphate/metformin hydrochloride tablets are recommended for dietary administration.

In this study, we investigated the metrics such as recoveries, matrix effects, linear range, LLQ, stability by specificity, precision, and accuracy specifications to confirm the LC-MS/MS method. Sitagliptin and metformin concentrations in human plasma showed a good linear relationship within $1-500$ and 3-1500 $\mathrm{ng} / \mathrm{mL}$. The relative SD values of intra- and interday precision were both less than $10 \%$. As an open-label study, assessment of AEs may not have been sufficiently objective. In addition, as this study was designed as a bioequivalence trial, the pharmacokinetic metrics were obtained from young healthy adults.

\section{Conclusion}

We evaluated the pharmacokinetics of a new generic sitagliptin/metformin tablet compared with those of the originator formulation to establish bioequivalence. Both products showed good tolerability and a similar safety profile. The $90 \%$ CIs of the ratios of the GM of the test and reference formulations for $C_{\max }, \mathrm{AUC}_{0-t}$, and $\mathrm{AUC}$ $0_{0-\infty}$ were all within the predefined bioequivalence criteria range of $80-125 \%$, showing that the test formulation was bioequivalent to the reference formulation by any of the detection indicators used.

Acknowledgments The authors are grateful to Tonghua Dongbao Pharmaceutical Co., Ltd., China, for their support.

\section{Declarations}

Funding This work was supported by grants from the National Major Scientific and Technological Special Project for "Significant New Drugs Development" (2020ZX09201-018, 2017ZX09304-024).

Conflicts of interest PS, XL, TL, FS, YL, SL, XG, YM, YF, and YC have no conflicts of interest that are directly relevant to the content of this article.

Ethics approval This clinical study protocol was approved by the Medical Ethics Committee at the Affiliated Hospital of Qingdao University, and the trial was registered with the Clinical Trial Registry (trial ID: NCT04877106).

Consent to participate All subjects provided written informed consent.

Consent for publication All authors give the publisher the permission to publish the work. Subjects signed informed consent regarding publishing their data.

Availability of data and material The datasets generated and/or analyzed during the current study are available from the corresponding author on reasonable request.

Code availability Not applicable.

Author contributions All authors completed this study together. Xin Liu and Ping Shi planned and drafted the paper and contributed to data quality control, analysis, and interpretation. Ting Li and Fei-fei Sun recorded the AEs and compiled statistics on AEs. Yan-ping Liu and Shu-qin Liu contributed to data collection. Yu Cao provided methodological guidance and support with data interpretation. All authors reviewed and revised the manuscript.

Open Access This article is licensed under a Creative Commons Attribution-NonCommercial 4.0 International License, which permits any 
non-commercial use, sharing, adaptation, distribution and reproduction in any medium or format, as long as you give appropriate credit to the original author(s) and the source, provide a link to the Creative Commons licence, and indicate if changes were made. The images or other third party material in this article are included in the article's Creative Commons licence, unless indicated otherwise in a credit line to the material. If material is not included in the article's Creative Commons licence and your intended use is not permitted by statutory regulation or exceeds the permitted use, you will need to obtain permission directly from the copyright holder. To view a copy of this licence, visit http://creativecommons.org/licenses/by-nc/4.0/.

\section{References}

1. Whiting DR, Guariguata L, Weil C, Shaw J. IDF Diabetes Atlas: Global estimates of the prevalence of diabetes for 2011 and 2030. Diabetes Res Clin Pract. 2011;94(3):311-321.

2. Dai Q, Wang Z. Investigation of diabetes status in China. Guide China Med. 2011;9(13):206-8.

3. Stumvoll Mm, Goldstein BJ, van Haeften TW. Type 2 diabetes: principles of pathogenesis and therapy. The Lancet. 2005;365(9467):1333-1346.

4. Pfeiffer AFH, Klein HH. The treatment of type 2 diabetes. Dtsch Arztebl Int. 2014;111(5):69-82.

5. Turner RC, Cull CA, Frighi V, et al. Glycemic control with diet, sulfonylurea, metformin, or insulin in patients with type 2 diabetes mellitus: progressive requirement for multiple therapies (UKPDS 49). UK Prospective Diabetes Study (UKPDS) Group. JAMA 1999; 281: 2005-12

6. Sohita S. Sitagliptin: a review of its use in the management of type 2 diabetes mellitus. Drugs. 2010;70(4):489-512;.

7. Scott LJ. Sitagliptin: a review in type 2 diabetes. Drugs. 2017;77(2):209-224.
8. Goldstein Barry J, Feinglos Mark N, Lunceford Jared K, Johnson Jeremy, Williams-Herman Debora E. Effect of initial combination therapy with sitagliptin, a dipeptidyl peptidase-4 inhibitor, and metformin on glycemic control in patients with type 2 diabetes. Diabetes Care. 2007;30(8).

9. Chwieduk CM. Sitagliptin/metformin fixed-dose combination: in patients with type 2 diabetes mellitus. Drugs. 2011;71(3):349-61.

10. General Assembly of the World Medical, A. World Medical Association Declaration of Helsinki: ethical principles for medical research involving human subjects. J Am Coll Dent. 2014;81(3):14-8.

11. Switula D. Principles of good clinical practice (GCP) in clinical research. Sci Eng Ethics. 2000;6(1):71-7.

12. Seyoum B. Sitagliptin and metformin-novel combination therapy. Expert Opin Pharmacother. 2011;12(4):641-646;.

13. Williams-Herman J, Teng L, Davies K, Goldstein A. Efficacy and safety of initial combination therapy with sitagliptin and metformin in patients with type 2 diabetes: a 54-week study. Curr Med Res Opin. 2009;25(3):569-583.

14. Sanchez-Rangel E, Inzucchi SE. Metformin: clinical use in type 2 diabetes. Diabetologia. 2017;60(9):1586-1593.

15. Seyoum B. Sitagliptin and metformin-novel combination therapy. Expert Opin Pharmacother. 2011;12(4):641-6.

16. Yang W, Guan Y, Shentu Y, Li Z, Johnson-Levonas AO, Engel SS, Kaufman KD, Goldstein BJ, Alba M. The addition of sitagliptin to ongoing metformin therapy significantly improves glycemic control in Chinese patients with type 2 diabetes. J Diabetes. 2012;4(3):227-37.

17. Scheen AJ. Pharmacokinetic and pharmacodynamic evaluation of sitagliptin plus metformin. Expert Opin Drug Metab Toxicol. 2010;6(10):1265-76. 